\title{
EXPERIMENTAL APPROACH FOR REMOVAL OF PETROL FROM GROUNDWATER USING STEAM INJECTION TECHNIQUE WITH VIBRATION EFFECT
}

\author{
Adegbola A.A, Olawale O.A, Ajao T.O, Oguindele K.A., Raheem R.A. \\ Ladoke Akintola University of Technology, Ogbomoso, Oyo State
}

\begin{abstract}
The major source of drinking water is derived from extraction of groundwater out of aquifers in the ground subsurface. However, aquifers are often faced with the problem of contamination from industrial wastes, oil spillage and other human wastes which tend to release harmful substances into the water. This research work entails the experimental investigation of vibration effect on remediation of polluted groundwater using steam injection. Laboratory experiment was set up using petrol as a separate phase from the water phase as typical in an aquifer and experiment carried out. Vibration with frequency of 3.375 Hertz and 6.75 Hertz was used along with the steam injection process. The steam generated by the steam boiler was injected into the sand box at a pressure of 2.4 bar and temperature of $1440 \mathrm{C}$ using $300 \mathrm{ml}$ as initial volume of the contaminant. The experimental result for recovery efficiency of petrol using steam injection only was $56 \%$ while that of Steam Injection with vibration frequency at 3.375$6.75 \mathrm{Hertz}$ yielded $60.67 \%-62.67 \%$. The experiment carried out showed that steam injection technique is effective in the removal of pollutant in groundwater. The combined application of steam injection with vibration appreciably enhances groundwater remediation.
\end{abstract}

Keywords: Petrol, Steam injection, Recovery efficiency, Remediation, Vibration

\section{INTRODUCTION}

Groundwater is the water present below the ground surface that saturates the pore space in the subsurface. Globally, about 25-40 percent of the world's drinking water is drawn from boreholes and dug wells and all these derive their supply from groundwater, and their roles in water supply are ever growing. Groundwater is generally and widely used in national welfare of many countries for different purposes like: portable water supply for the population and livestockbreeding, industrial water supply, irrigation, biological use (mineral water), as a raw material for extracting valuable components, such as iodine and bromine (industrial water) and for central heating (thermal power water).

Most times, groundwater is clean, but groundwater can become polluted, or contaminated as a result of human activities or as a result of natural conditions. Current practices impact groundwater quality, such as the over application of fertilizer or pesticides, spills from industrial operations, infiltration from urban runoff, and leaking from landfills. Also, the many and diverse activities of humans produce innumerable waste materials and by-products. The most common contaminants in groundwater are the so-called Non-Aqueous Phase Liquids (NAPL). NAPLs denote mostly chlorinated solvents, aromatics, oils and poly aromatics which are immiscible and low soluble in water. In relation to the density of water, NAPLs can be classified into Light Non-Aqueous Phase Liquids (LNAPL) and Dense Non-Aqueous Phase Liquids (DNAPL).

Environmental pollution is currently one of the most important issues facing humanity. It has increased exponentially over the past few years and is reaching alarming proportions in terms of its effect on living creatures. Hydrocarbon compounds found in crude oil are considered among the pollutants that have the most adverse effect on nature, man and animals as they pollute groundwater resources making the water unusable for humans and unsuitable for plants. However, this increasing groundwater pollution in our world today and its various adverse effects caused the necessity for developing ways and methods for 


\section{International Journal of Engineering Applied Sciences and Technology, 2021 \\ Vol. 6, Issue 4, ISSN No. 2455-2143, Pages 85-98 \\ Published Online August 2021 in IJEAST (http://www.ijeast.com)}

improving the quality and level of purification of groundwater.

Remediation techniques can be classified into three groups namely: Biological methods e.g. bio-augmentation, Bio-sparging (Liu, et al.), Chemical Method e.g. chemical precipitation, Carbon absorption and Physical (Thermal) methods e.g. Surfactant enhanced recovery, Pump and Treat, Air sparging (Elder, Benson, \& Eykholt, 1999).dual phase extraction and others. Thermally enhanced remediation technologies are promising for the removal of contaminants at heavily contaminated sites (Eakin et al., 2010). The methods include injection of hot air, hot water or steam. The main reason for the wide application of thermal treatment is that the mobility of the contaminant increases at elevated temperatures (Costanza, Davis, Mulholland, \& Pennell, 2005). The single most important removal mechanism is increased vapour pressure. The high temperature dependence of vapour pressure leads to an increased fraction of the contaminants in the gas phase which increases the ease of extracting contaminants in soil vapour (Heron et al., 2005). Currently many researchers are evaluating the applicability of thermal remediation recovery technology to the remediation of NAPL sites. Current reviews of the development of this technology for NAPL removal (Jawitz et al. 1998) and other hazardous waste site remediation (Sims, 1990) are available. Information from these sources is also applicable to LNAPL (Light NonAqueous Phase Liquids) and DNAPL (Dense NonAqueous Phase Liquids) site remediation

Steam injection, also termed steam or thermal enhanced extraction, was initially developed by the petroleum industry for enhancing oil recovery, and has more recently been adapted to remediate soil and aquifers (Heron, Carroll, \& Nielsen, 2005). Steam injection is a possible technique which have been investigated (Davis and Lien, 1998; Fulton et al, 1991; Hunt et al, 1988; Johnson and Leuschner, 1992; Sims, 1990; Udell, 1992; U.S.EPA, 1992a). Steam injection has been applied at some sites in the USA (USEPA, 2004). It has been applied in unsaturated as well as saturated zones (Uzgiris et al. 1995) and is generally more efficient in porous media such as sand (Ludvigsen et al. 1998) than in low permeable soils (Balshaw-Biddle et al., 2000). Steam injection remediation techniques have potential application for increased removal of NAPL in both the saturated and unsaturated zones. This technique has been evaluated in a relatively limited number of field scale studies (Balba et al. 1998). Usage of this steam for mobility control in steam injection shows an increase in the pollutant recovery (Lie, 2013). Steam injection technique is one of the major forms of efficient groundwater remediation techniques. It involves the use of high pressure steam to recover organic contaminants by injecting the steam with increasing temperature of the sub-surface, this leads to a very fast and effective remediation of the contaminated groundwater (Allawzi et al., 2008).

Numerous theoretical and experimental investigations have demonstrated that vibration can have a significant effect on the flow of nonNewtonian fluids in general (kazakia and Rivlin, 1978; Mena et al., 1979; Rahaman and Ramkissoon, 1995; del Rio et al., 1998; Tsiklauri and Beresnev, 2001a, 2001b). Numerous observations and laboratory experiments suggest that elastic vibrations can significantly enhance transport of non-aqueous phase liquids (NAPLs) in porous media. There are numerous laboratory experiments and field observations that provides evidence that sonic simulation can significantly enhance fluid flow in porous media (Beresnev and Johnson, 1994a). Our analysis suggests that in the low-frequency range, capillary forces and nonlinear rheology of the fluid may be predominant mechanisms of vibratory stimulation. Consequently, a model of these mechanisms is built to explain the effect of sonic waves on fluid percolation. The model shows that the lowfrequency elastic waves of relatively low intensity can significantly enhance the flow rate of a yield stress fluid under small external pressure gradients and aid in the mobilization of entrapped NAPL blobs by reducing the value of the threshold gradient needed to displace the fluid. Effect of elastic vibrations on fluid flow in a porous medium composed of elastic channel structures has been addressed by Lie (2013) and has been shown to produce flow enhancement, and only at resonant frequencies, which strongly depend on the porosity of the medium. Because of natural variations in porosity and limited variability in the frequency of operation of available seismic sources Costanza, et al. (2005), this resonant method appears to be of little applicability to realistic reservoir conditions. The subject of vibratory (sonic or seismic) stimulation of fluid flow in porous media has aroused increasing interest in the last decade, primarily in connection with the applications to enhanced oil recovery (EOR) and remediation of non-aqueous phase liquids (NAPL) contaminated aquifers. Compared to the other methods of EOR currently in use, the vibratory stimulation is ecologically clean and economic in its implementation, which promotes its further use Costanza, et al. (2005).

The combination of vibration with steam injection can result in a powerful method for 


\section{International Journal of Engineering Applied Sciences and Technology, 2021 \\ Vol. 6, Issue 4, ISSN No. 2455-2143, Pages 85-98 \\ Published Online August 2021 in IJEAST (http://www.ijeast.com)}

pollutant degradation. The propagation of the waves in the medium induces cavitations and even violent collapse at high acoustic pressure (Mason and Lorimer, 2002). Among the physical effects of these collapses are the high rates of micro-mixing, the cleaning of the groundwater by dissolving the inhibiting layers. These effects results mainly in an enhancement of the solid-liquid mass transfer in the solution Borden, et al. (1992). In view of these, the use of vibration is a technologically advanced application of waves in the treatment of effluents, for accelerating the destruction of contaminants in the liquid phase Lie, S. H. (2013). Since the application of ultrasonic technology, it has been receiving wide attention by the world in waste water treatment and environmental remediation areas. The use of vibrational technology along with steam injection process is therefore verified to be very promising for the degradation persistent organic compounds in waste water as it is proven to been effective method for degrading organic effluent into less toxic compounds.

The aim of this research work is to investigate the effect of vibration on removal of petrol from groundwater using steam injection. Experimental investigation was carried out to study the removal of Light Non-Aqueous Phase Liquids (NAPL) from groundwater using steam injection with vibration effect.

\section{METHODOLOGY}

This remediation process involved the treatment of the water contaminated with petrol by removing the pollutant using steam injection with vibration effect in order to make the water harmless.

\subsection{Contaminant (Petrol)}

The contaminant chosen for this research work is Petrol which is an example of LNAPLs (Light Non-Aqueous Phase Liquids) and is a product of fractional distillation of crude oil that occur between $200^{\circ} \mathrm{C}$ and $350^{\circ} \mathrm{C}$ at atmospheric pressure, thereby resulting in a mixture of carbon chains that typically contain between 8 to 12 carbon atmospheric molecules (Table 1).

Table 1: Properties of the contaminant (Petrol)

\begin{tabular}{cc}
\hline \multicolumn{2}{c}{ Properties of Petrol } \\
\hline Colour & Light brown \\
Density & $737.22 \mathrm{~kg} / \mathrm{m}^{3}$ \\
Solubility & Increases as temperature rises i \\
iling point & $100^{\circ} \mathrm{F}-400^{\circ} \mathrm{F}$ \\
Viscosity & No change \\
Ignition temperature & $232^{\circ} \mathrm{C}$ \\
Smell & Fairly chocking
\end{tabular}

\subsection{Steam Boiler Working Principle}

The steam boiler consisted of a cylinder containing water, a section containing the burning charcoal which was the source of the heat for the steam generation, it also consisted of a blower supplying air to enhance the burning of the charcoal, a section containing the ash-tray which received the ash which was the waste from the burnt charcoal, a pressure gauge which showed the pressure level in the steam boiler, a flow control valve controlling the flow pressure level, Lagging serving as insulator to prevent any heat loss. The generated heat was transferred to the water in the cylinder to transform it to steam; this process produced saturated steam at a rate varied according to the pressure above the pressure of boiling water. The higher the furnace temperature, the faster the rate of steam production. The steam was then

passed through the steam injector which is a type of pump that uses venture effect incorporated with the steam boiler to convert the pressure energy of a motive fluid.

The water approached its boiling condition as the temperature in the steam boiler increases, some water molecules attained enough 


\section{International Journal of Engineering Applied Sciences and Technology, 2021 \\ Vol. 6, Issue 4, ISSN No. 2455-2143, Pages 85-98 \\ Published Online August 2021 in IJEAST (http://www.ijeast.com)}

kinetic energy to reach velocities that allow them to momentarily escape from the liquid into the space above the surface, before falling back into the liquid. Further heating caused greater excitation and the number of molecules with enough energy to leave the liquid increases. As the water was heated to its boiling point, bubbles of steam form within it and rose to break through the surface. When the number of molecules leaving the liquid surface is more than those re-entering, the water freely evaporated. At this point it has reached boiling point or its saturation temperature, as it has saturated. Since the pressure remained constant, adding more heat did not cause the temperature to rise any further but caused the water to form saturated steam which was the steam input into the sandbox.

This steam remediation experimental setup was designed for steam injection technique only; it consisted of the following parts;

- Steam boiler: This was the principal part of the setup as it was the source of the generated steam used for the remediation process.

- Inlet pipe: This was the passage for the steam being generated from the boiler to the sand box where the soil sample was.

- Sand box: This was the box in which the soil sample containing the mixture of water and contaminant was placed.

- $\quad$ Outlet pipe: This was the passage that led to the condenser through which the contaminant was recovered.

- Thermometer: This was used to monitor the temperature of the steam.

- Pressure gauge: This was used to monitor the pressure of the steam boiler

\subsection{Sand-box description}

This is a stainless steel box of dimensions $110 \times 60 \times 8.5 \mathrm{~cm}$ which was filled with a mixture of fine and coarse sand and stones of different sizes representing an ideal soil profile which contained the measured quantity of the selected contaminant i.e. LNAPLs (Petrol). The front view of the sand-box was made of a transparent glass panel to allow proper visual inspection of the sand profile and the steam injection process which was taking place in the sandbox. A thermometer was used to monitor the temperature of the incoming steam, an electric motor having a specified rating was incorporated to the sand-box and was used to produce the vibrational effect. The condenser was connected to the sand box at the outlet. The phase separator was used to separate the condensed water and the condensed contaminants.

\subsection{Experimental Procedure for Steam} Injection

In the experimental setup shown in fig 1, the specified volume of contaminant $(300 \mathrm{ml})$ was put into the sand box which contained the ideal soil profile and water. Pressure enough to channel the steam (2.4bar) was allowed to build up in the steam boiler, the pressure was monitored with the pressure gauge and when it reached the required pressure (2.4bar), the saturated steam generated from the steam boiler was then injected into the sandbox through the inlet pipe. The injection rate was controlled by adjusting the pressure valve which was there for safety purpose to prevent bursting of the cylinder. The contaminant was then displaced by the steam from the sandbox to a condenser where the steam and the contaminant were converted to liquid form and then passed through a phase separator, where the water and contaminant produced will be collected separately in a funnel. The effluent (water and contaminant in steam form) was collected in the measuring cylinder and allowed to stand for a period of time for gravitational segregation of the contaminant from water, where water settled at the bottom and petrol was at the top since the density of water is more than that of petrol.

The recovery efficiency was then calculated by comparing the recovered contaminant, with the initial contaminant. Percentage recovery efficiency was then calculated subsequently as shown below;

Percentage Recovery Efficiency = $\frac{\text { Recovered volume of contaminant }}{\text { Initial volume of contaminant }} \times 100 \%$

\subsection{Mechanism of ground water remediation using Steam injection with Vibration effect}

The experiment was used to investigate the effect of vibration on effectiveness of steam injection technique on groundwater remediation. The experiment was designed using a vibration producing electric motor and steam injection mechanism combined together to carry out the remediation process of the water contaminated with LNAPLs (petrol). This device (Table 1) created a form of vibration in the liquid-mixture within the sandbox. It had a control for regulating the frequency of vibration, the frequency range of 3.375 Hertz - 6.75Hertz. This device created a form of vibration in the liquid-mixture within the sandbox. It has a control for regulating the frequency of vibration. The effects of vibration on 


\section{International Journal of Engineering Applied Sciences and Technology, 2021 \\ Vol. 6, Issue 4, ISSN No. 2455-2143, Pages 85-98 \\ Published Online August 2021 in IJEAST (http://www.ijeast.com)}

groundwater remediation is significant as it disturbs the soil pore structure and thereby enhances the transportation of the contaminants, it prevents the settling or hiding of the contaminants in unreachable parts of the soil pore structure and therefore increases the recovery efficiency.

Before each experimental was an as usual, the sand box was equilibrated for one day before steam injection was initiated. The aquifer (sand box) was filled with polluted water (oily water). The experiment was performed using the vibration devise at varying frequency and steam injection mechanism combined together to remediate the water contaminated with petrol. The saturated steam that is being generated from the steam boiler was allowed to come into the test chamber through the injection port by controlling the flow rate through a tap. Vibration devise was switched on to generate vibration effects at frequency range intervals. As the contaminated area was heated, its temperature will be measured at different time interval. The vaporized petrol was transported to the heat front where it will condense and accumulated emplaced petrol was recovered as separate phase from the top of the water table in the phase separator. When NAPL (petrol) no longer condensed in the phase separator, the entire sand packing was heated to steam temperature but no more petrol was recovered. The condensate (which contained the recovered contaminant and some water) in the phase separator was allowed to stay for some time to allow for separation of water from the contaminant. The final recovered contaminant was measured with the measuring cylinder.

Table 1. Electric motor description (source of vibration effect)

\begin{tabular}{ll}
\hline Property & Rating \\
\hline Voltage & 12 volts \\
Torque & $3.63 \mathrm{Ncm}$ \\
Speed of rotation & $202.5 \mathrm{rpm}-405 \mathrm{rpm}$ \\
Current & $0.32 \mathrm{amperes}$ \\
Power & $1.53 \mathrm{~W}$ \\
Frequency & $3.375 \mathrm{~Hz}-6.75 \mathrm{~Hz}$ \\
\hline
\end{tabular}




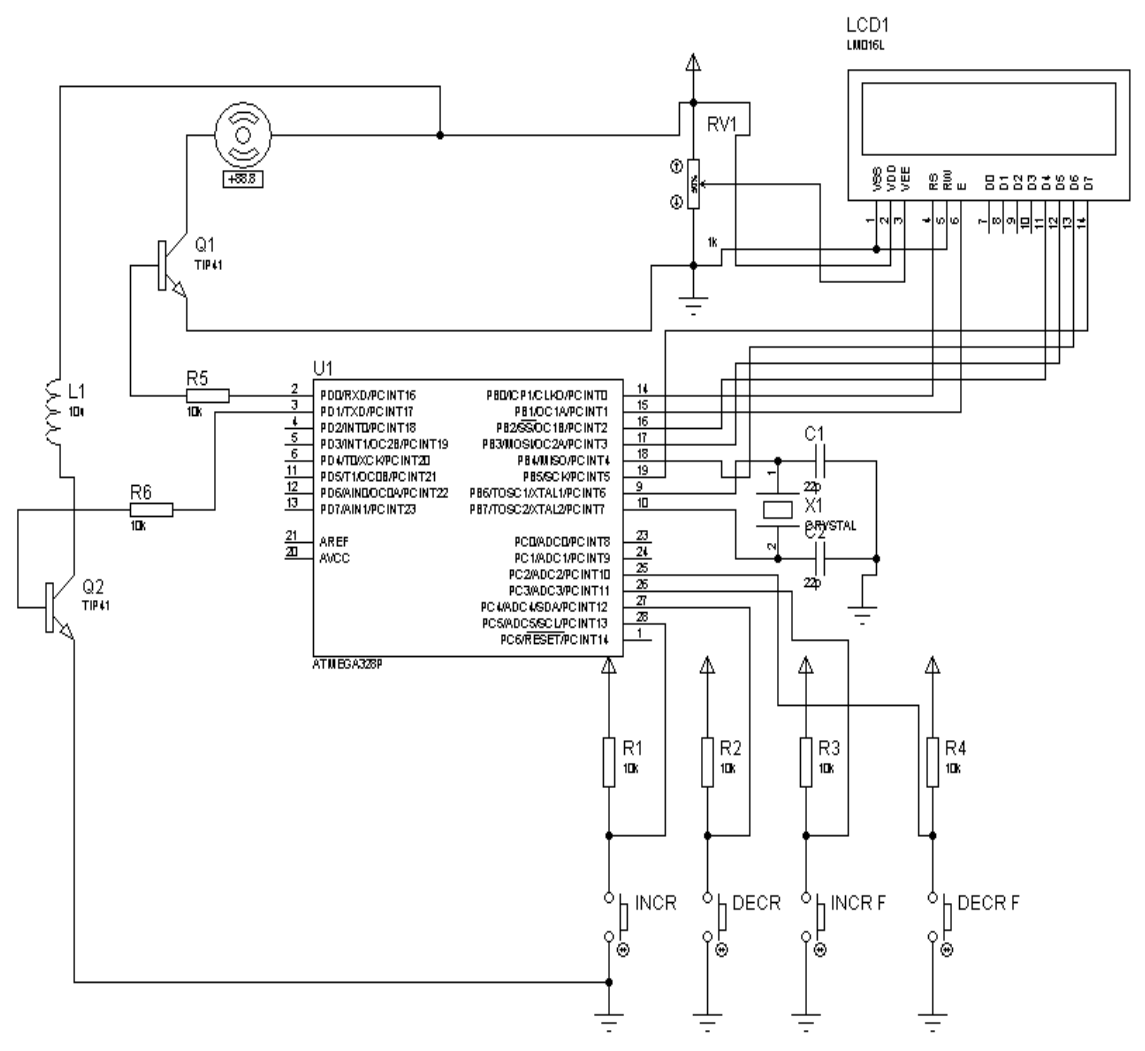

Fig. 1: Circuit Diagram of the Electric Motor

\subsubsection{Experimental procedure for vibration effect on steam injection}

- The soil sample was placed in the sand box.

- Water was poured into the sandbox.

- The specified amount of contaminant (300ml) was measured and put into the sand box.

- Pressure enough to channel steam was allowed to build up.
- The vibration producing electric motor was switched on.

- Steam was injected into the sandbox.

- The effluent (water and contaminant in steam form) was collected in the measuring cylinder and allowed to stand for a period of time for gravitational segregation of the contaminant from water, where water settled at the bottom and petrol was at the top since the density of water is more than that of petrol.

- The recovery efficiency was then calculated by comparing the recovered contaminant, with the initial contaminant. Percentage recovery efficiency was then calculated. 


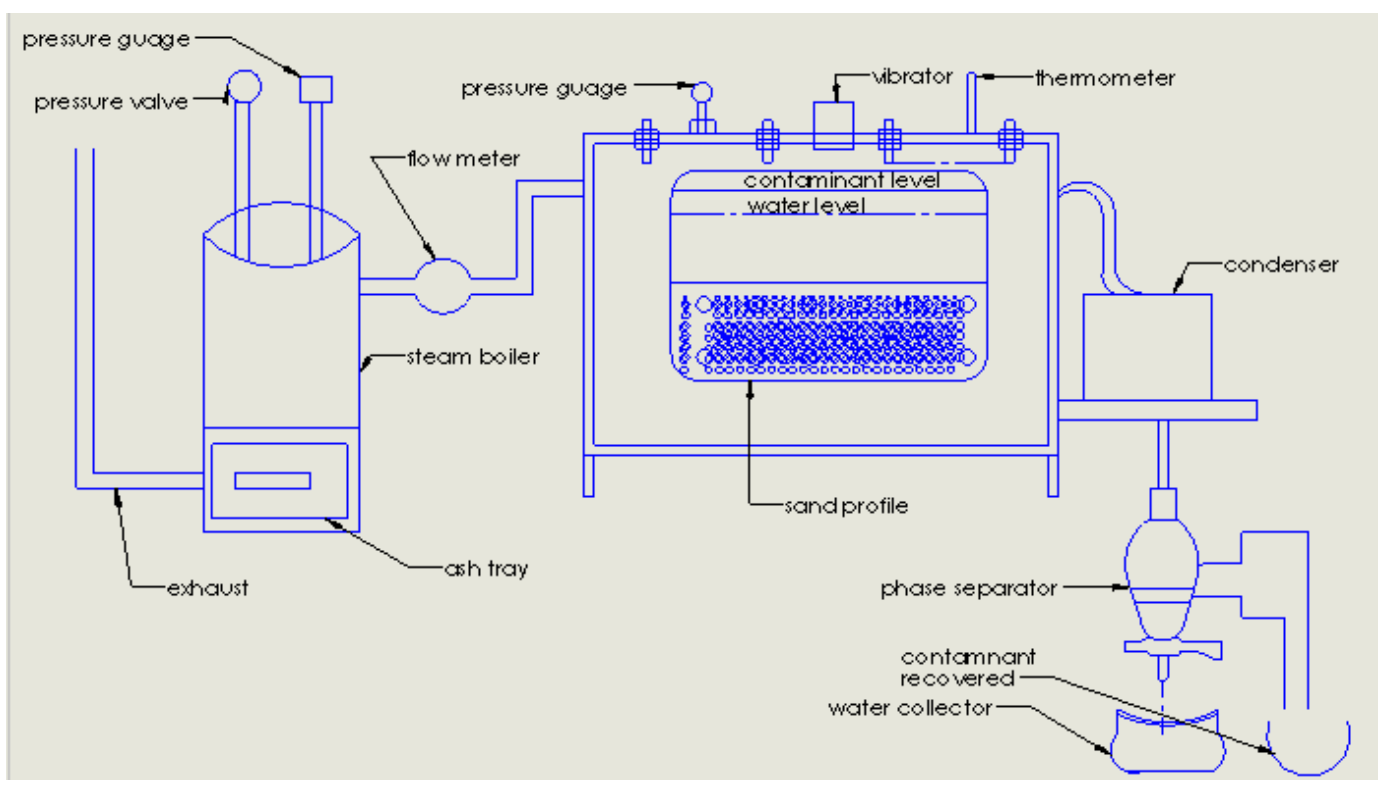

Fig. 2: Diagram for the experimental setup of vibrational effect on steam injection

\section{RESULTS AND DISCUSSION}

The results of three experiments are reported. The experiment with pure steam Injection was carried out using petrol as contaminant. Two additional experiments were which involve the effects of vibration of varying frequency of 3.375 Hertz - 6.75 Hertz on groundwater remediation using steam injection were also carried out. The following results were obtained from the experimental approach for remediation of LNAPLs (petrol) from groundwater, using steam injection only and steam injection with vibration effect (Table 2-4 and figure 3-6). The frequency of vibration being 3.375 Hertz and 6.75 Hertz and the initial volume of the contaminant (petrol) being $300 \mathrm{ml}$. The results which are tabulated are shown below, likewise, the recovery efficiency of each experiment with the corresponding time taken are represented in tables and are shown below.

Table 2: The result of groundwater remediation process using steam injection only

\begin{tabular}{ccc} 
Time (hour) & Amount Recovered (ml) & Recovery Efficiency (\%) \\
\hline 0 & 0 & 0 \\
1.13 & 54 & 17.30 \\
2.28 & 93 & 31.00 \\
3.03 & 128 & 47.67 \\
4.13 & 147 & 49.00 \\
5.05 & 168 & 56.00
\end{tabular}


International Journal of Engineering Applied Sciences and Technology, 2021

Vol. 6, Issue 4, ISSN No. 2455-2143, Pages 85-98

Published Online August 2021 in IJEAST (http://www.ijeast.com)

\section{Steam Injection}

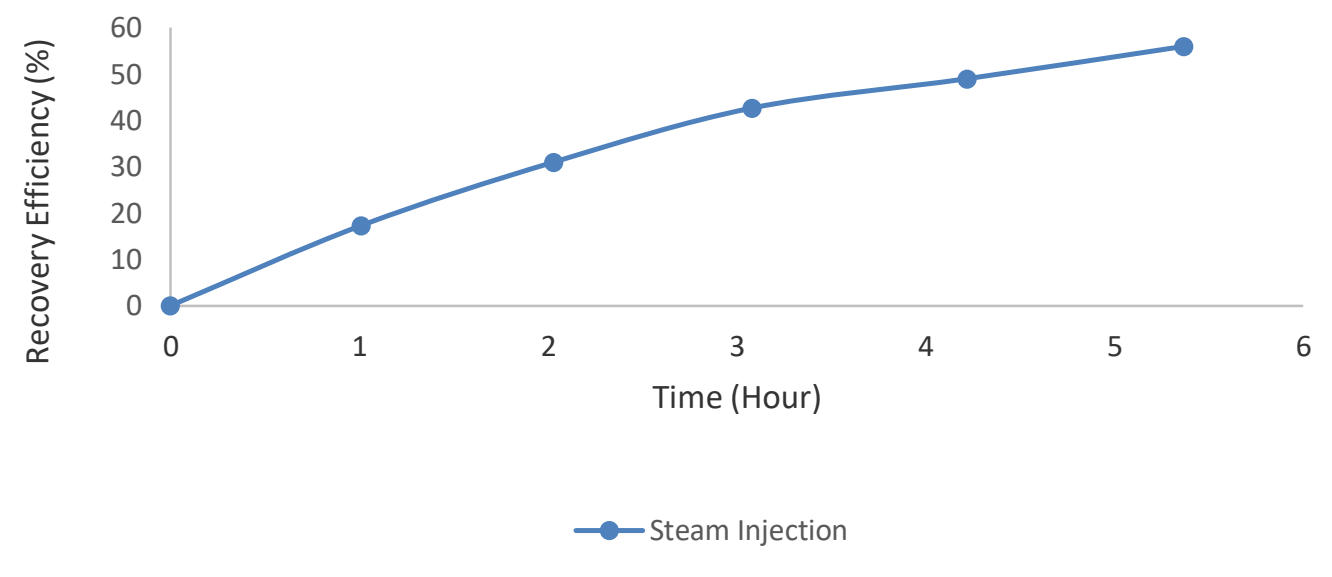

Fig. 3: Graphical representation of the recovery efficiency of groundwater remediation process using steam injection only

Table 3: The result of remediation of water contaminated with petrol using steam injection with vibration effect of frequency 3.375 Hertz

\begin{tabular}{ccc}
\hline Time (hour) & Amount Recovered (ml) & Recovery Efficiency (\%) \\
\hline 0 & 0 & 0 \\
1.10 & 86 & 28.67 \\
2.03 & 122 & 40.70 \\
3.08 & 153 & 51.00 \\
4.22 & 175 & 58.30 \\
5.37 & 182 & 60.70 \\
\hline
\end{tabular}


International Journal of Engineering Applied Sciences and Technology, 2021

Vol. 6, Issue 4, ISSN No. 2455-2143, Pages 85-98

Published Online August 2021 in IJEAST (http://www.ijeast.com)

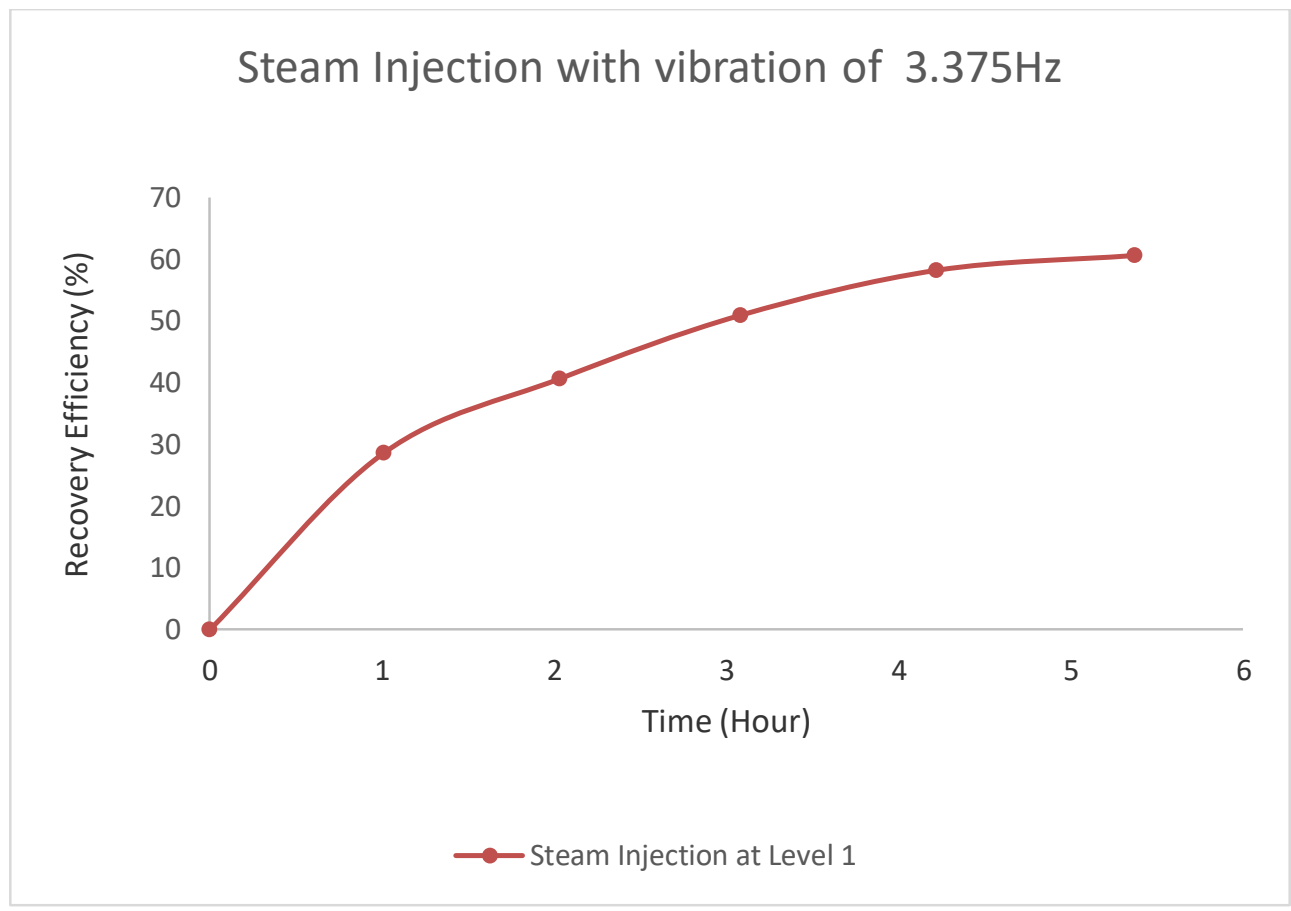

Fig. 3: Graphical representation of the recovery efficiency of groundwater remediation process using steam injection along with vibration of frequency $3.375 \mathrm{Hertz}$

Table 4: the result of remediation of water contaminated with petrol using steam injection with vibration effect of frequency $6.75 \mathrm{Hertz}$

\begin{tabular}{lcc}
\hline Time (hour) & Amount Recovered (ml) & Recovery Efficiency (\%) \\
\hline 0 & 0 & 0 \\
1.13 & 92 & 30.67 \\
2.07 & 127 & 42.30 \\
3.23 & 157 & 52.30 \\
4.15 & 176 & 58.70 \\
5.20 & 188 & 62.67 \\
\end{tabular}


International Journal of Engineering Applied Sciences and Technology, 2021

Vol. 6, Issue 4, ISSN No. 2455-2143, Pages 85-98

Published Online August 2021 in IJEAST (http://www.ijeast.com)

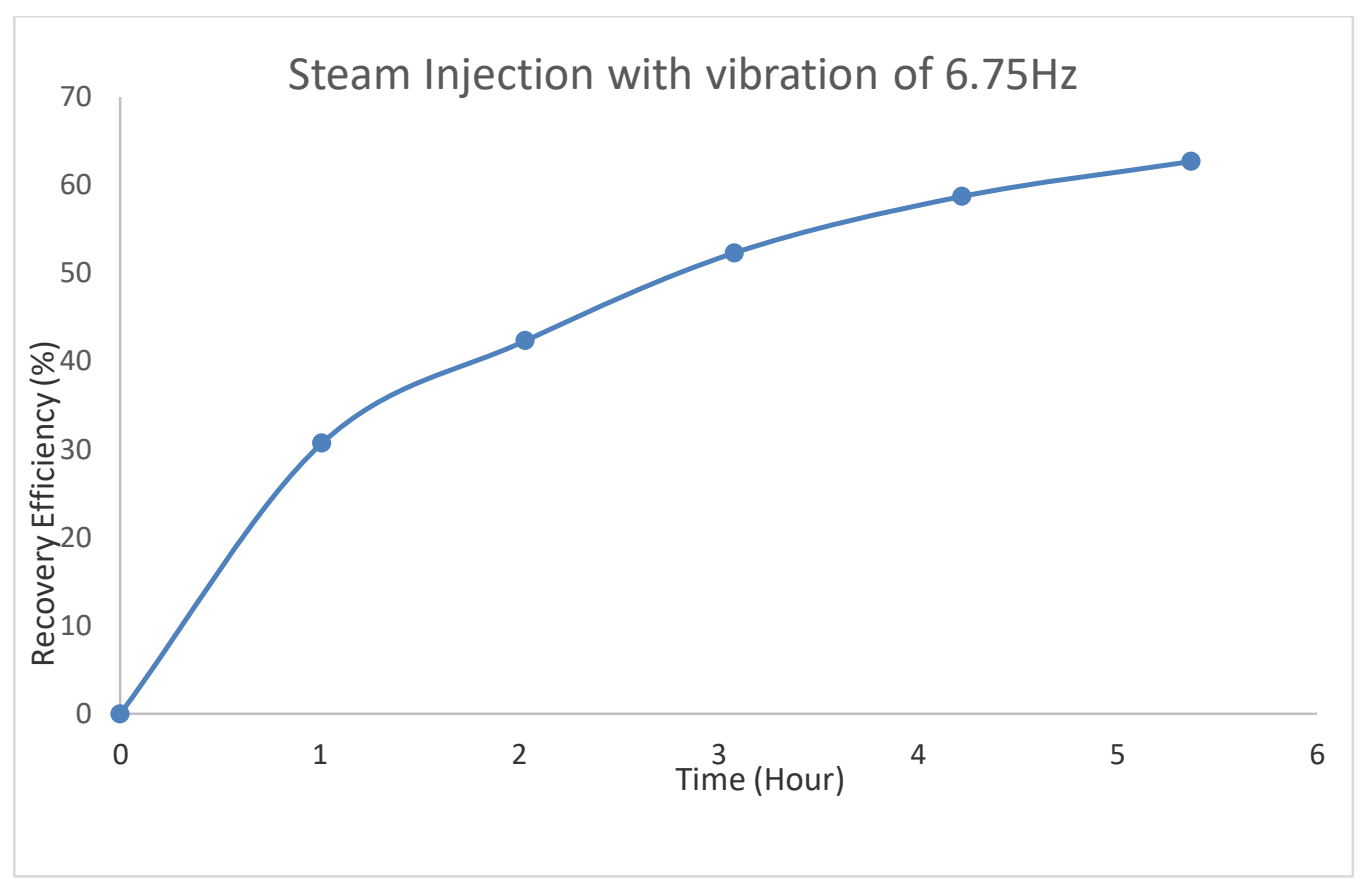

Fig. 5: Graphical representation of the recovery efficiency of groundwater remediation process using steam injection along with vibration of frequency $6.75 \mathrm{Hertz}$

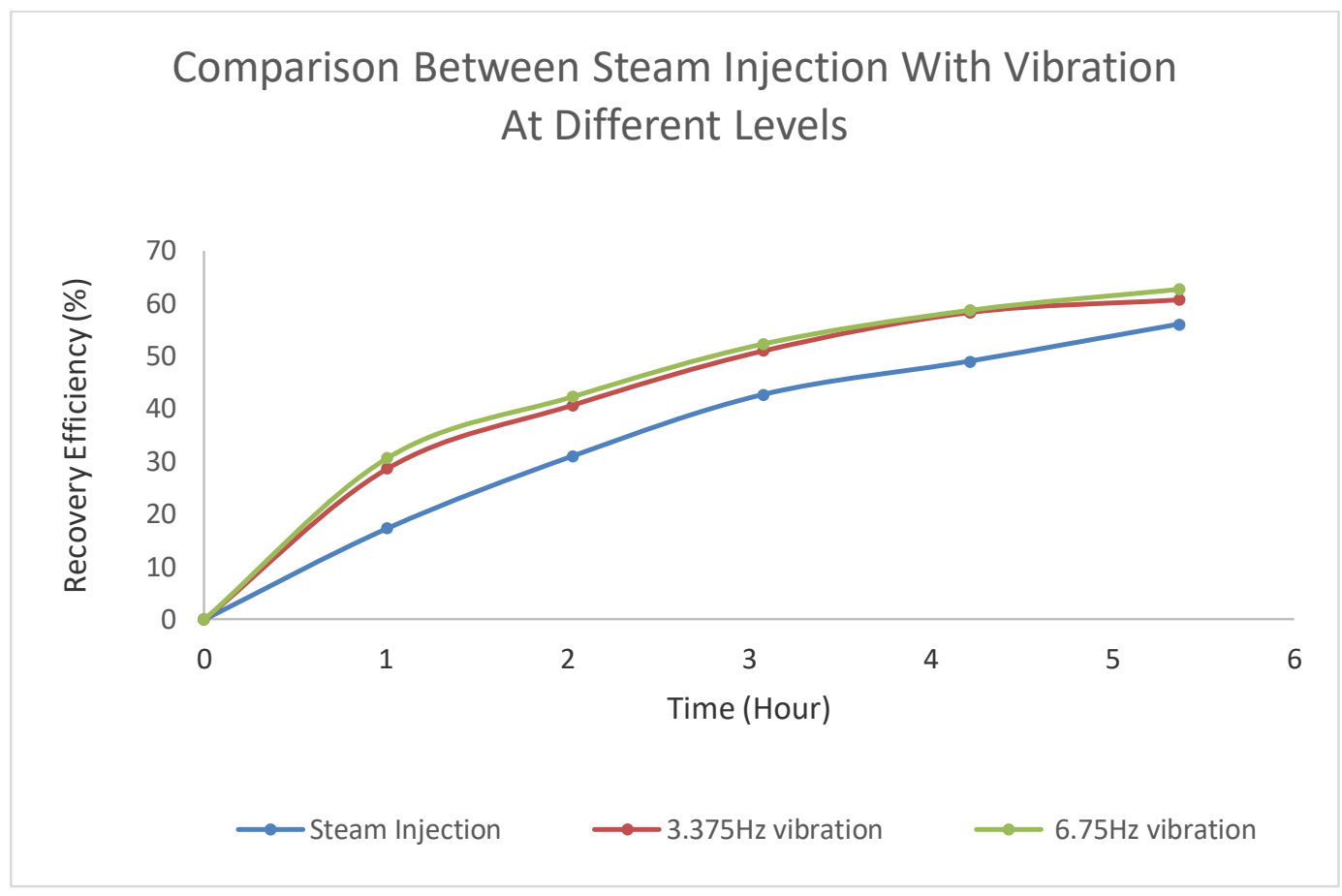

Fig. 6: Comparison of the results and the recovery efficiency of groundwater remediation process using steam injection along with vibration of frequency $3.375 \mathrm{Hertz}$ and $6.75 \mathrm{Hertz}$

\section{CONCLUSION}

In this experimental project, the experimental procedure remediation of water contaminated with petrol using steam injection was carried out. The process involved the injection of steam into an ideal soil profile containing a mixture of water and the contaminant (petrol). A mechanism for improvement of steam injection using vibration effect was then carried out, where the effect of the vibration was investigated at frequency of $3.375 \mathrm{Hertz}$ and $6.75 \mathrm{Hertz}$ 


\section{International Journal of Engineering Applied Sciences and Technology, 2021 \\ Vol. 6, Issue 4, ISSN No. 2455-2143, Pages 85-98 \\ Published Online August 2021 in IJEAST (http://www.ijeast.com)}

respectively. The experimental result for recovery efficiency of petrol using steam injection only was $56 \%$ while the experimental result for that of steam injection along with vibration effect at frequency $3.375 \mathrm{Hertz}$ was $60.7 \%$ and that of frequency $6.75 \mathrm{Hertz}$ was $62.67 \%$. The mass and volume not accounted for accounted for must be due to loss during emplacement, sorption and measurement uncertainties during recovery.

The results confirmed that steam injection is effective for the remediation of groundwater contaminated with non aqueous phase liquids (NAPLs) and that recovery efficiency of steam injection can be highly improved when vibration is incorporated with the steam injection mechanism. Hence the combined application of steam injection with vibration enhances groundwater remediation.

\section{REFERENCES}

Allawzi, M. A., \& Al-Jarrah, N. (2008). Study of the Effect of Steam Injection on Crude Oil Displacement Yield from an Oil Contaminated Soil Bed. Jordan Journal of Civil Engineering, 2(3).

Balba, M., Al-Awadhi, N., \& Al-Daher, R. (1998). Bioremediation of oil-contaminated soil: microbiological methods for feasibility assessment and field evaluation. Journal of microbiological methods, 32(2), 155-164.

Balshaw-Biddle, K., Oubre, C., Ward, C. H., Dablow III, J., Pearce, J., \& Johnson, P. (2000). Steam and electroheating remediation of tight soils: Rice Univ., Houston, TX (US).

Borden, R. C., \& Kao, C.-M. (1992). Evaluation of groundwater extraction for remediation of petroleum-contaminated aquifers. Water Environment Research, 28-36.

Cohen, R. M., Mercer, J. W., Greenwald, R. M., \& Beljin, M. S. (1997). Design guidelines for conventional pump-and-treat systems: US Environmental Protection Agency, Office of Research and Development, Office of Solid Waste and Emergency Response.

Costanza, J., Davis, E. L., Mulholland, J. A., \& Pennell, K. D. (2005). Abiotic degradation of trichloroethylene under thermal remediation conditions. Environmental science \& technology, 39(17), 6825-6830.

Eakin, C. M., Morgan, J. A., Heron, S. F., Smith, T. B., Liu, G., Alvarez-Filip, L., . . Bouchon, C. (2010). Caribbean corals in crisis: record thermal stress, bleaching, and mortality in 2005. PloS one, 5(11), e13969.

Elder, C. R., Benson, C. H., \& Eykholt, G. R. (1999). Modeling mass removal during in situ air sparging. Journal of geotechnical and geoenvironmental engineering, 125(11), 947-958.

Heron, G., Carroll, S., \& Nielsen, S. G. (2005). Full-Scale Removal of DNAPL Constituents Using Steam-Enhanced Extraction and Electrical Resistance Heating. Groundwater Monitoring \& Remediation, 25(4), 92-107.

Jawitz, J. W., Annable, M. D., Rao, P., \& Rhue, R. D. (1998). Field implementation of a Winsor type I surfactant/alcohol mixture for in situ solubilization of a complex LNAPL as a single-phase microemulsion. Environmental science \& technology, 32(4), 523-530.

Kaslusky, S. F., \& Udell, K. S. (2005). Coinjection of air and steam for the prevention of the downward migration of DNAPLs during steam enhanced extraction: An experimental evaluation of optimum injection ratio predictions. Journal of contaminant hydrology, 77(4), 325-347.

Lie, S. H. (2013). Diffusion as an Oil Recovery Mechanism During CO2 Injection in Fractured Reservoirs.

LIU, S.-S., CHEN, Z.-1., LIU, B., MA, D., XU, Y.X., \& PENG, X.-c. (2013). Field Demonstration of Soil Vapor Extraction on Diesel Fuel Contaminated Site. Journal of Soil and Water Conservation, 1, 036.

Ludvigsen, L., Albrechtsen, H.-J., Heron, G., Bjerg, P. L., \& Christensen, T. H. (1998). Anaerobic microbial redox processes in a landfill leachate contaminated aquifer (Grindsted, Denmark). Journal of contaminant Hydrology, 33(3), 273-291.

Prats, M. (1989). Operational aspects of steam injection processes. Developments in Petroleum Science, 17, 351-400.

Sims, R. C. (1990). Soil remediation techniques at uncontrolled hazardous waste sites. Journal of the Air \& Waste Management Association, 40(5), 704732.

Sleep, B. E., \& Ma, Y. (1997). Thermal variation of organic fluid properties and impact on thermal remediation feasibility. Soil and Sediment Contamination, 6(3), 281-306. 
Published Online August 2021 in IJEAST (http://www.ijeast.com)

USEPA, U. (2004). Air quality criteria for particulate matter. Volume II of II.

Uzgiris, E. E., Edelstein, W. A., Philipp, H. R., \& Iben, I. T. (1995). Complex thermal desorption of PCBs from soil. Chemosphere, 30(2), 377-387.
Willman, B., Valleroy, V., Runberg, G., Cornelius, A., \& Powers, L. (1961). Laboratory studies of oil recovery by steam injection. Journal of Petroleum Technology, 13(07), 681-690.

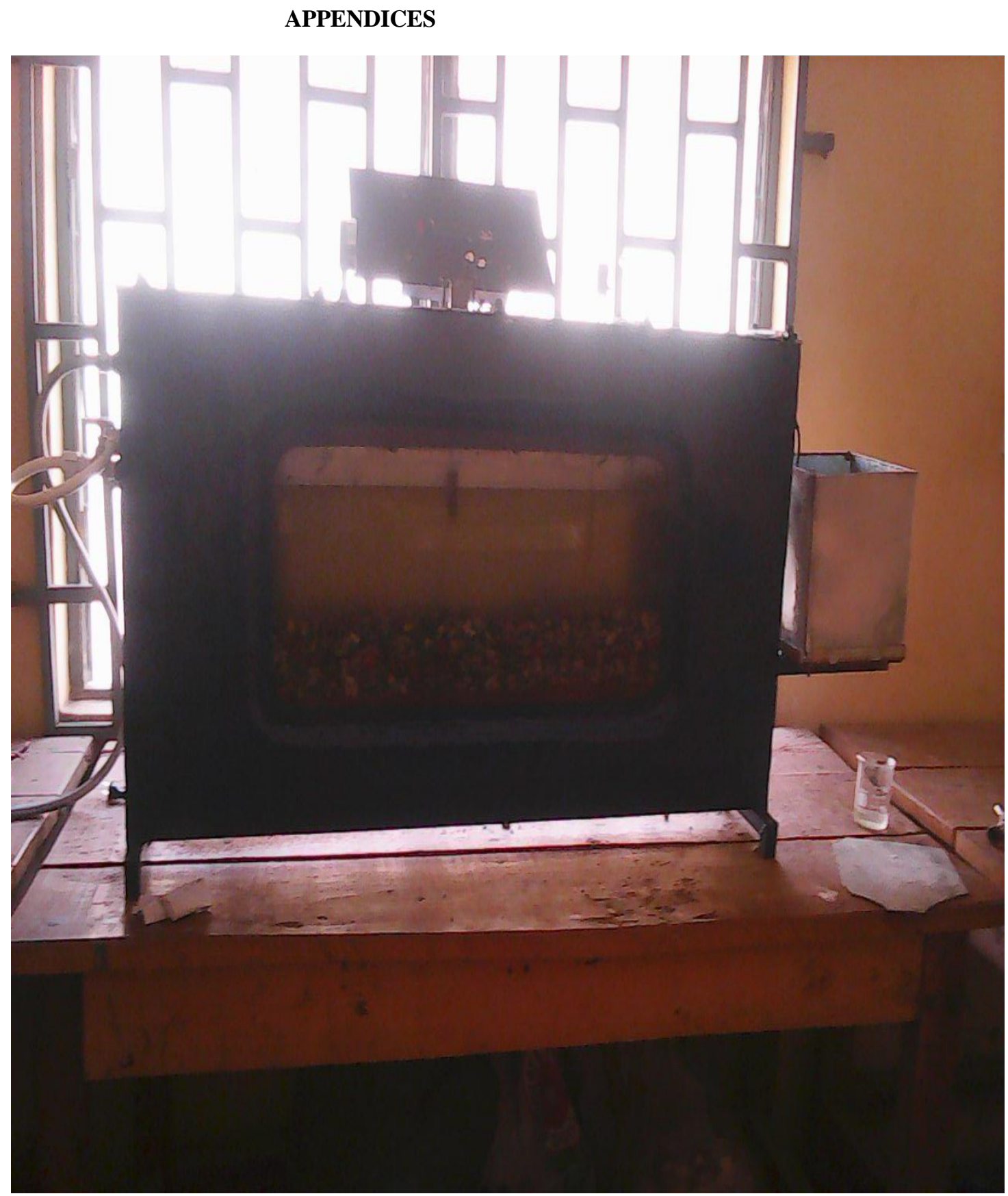

Plate 1: Sandbox containing the ideal soil profile and the mixture of water and the contaminant 
International Journal of Engineering Applied Sciences and Technology, 2021 Vol. 6, Issue 4, ISSN No. 2455-2143, Pages 85-98

Published Online August 2021 in IJEAST (http://www.ijeast.com)

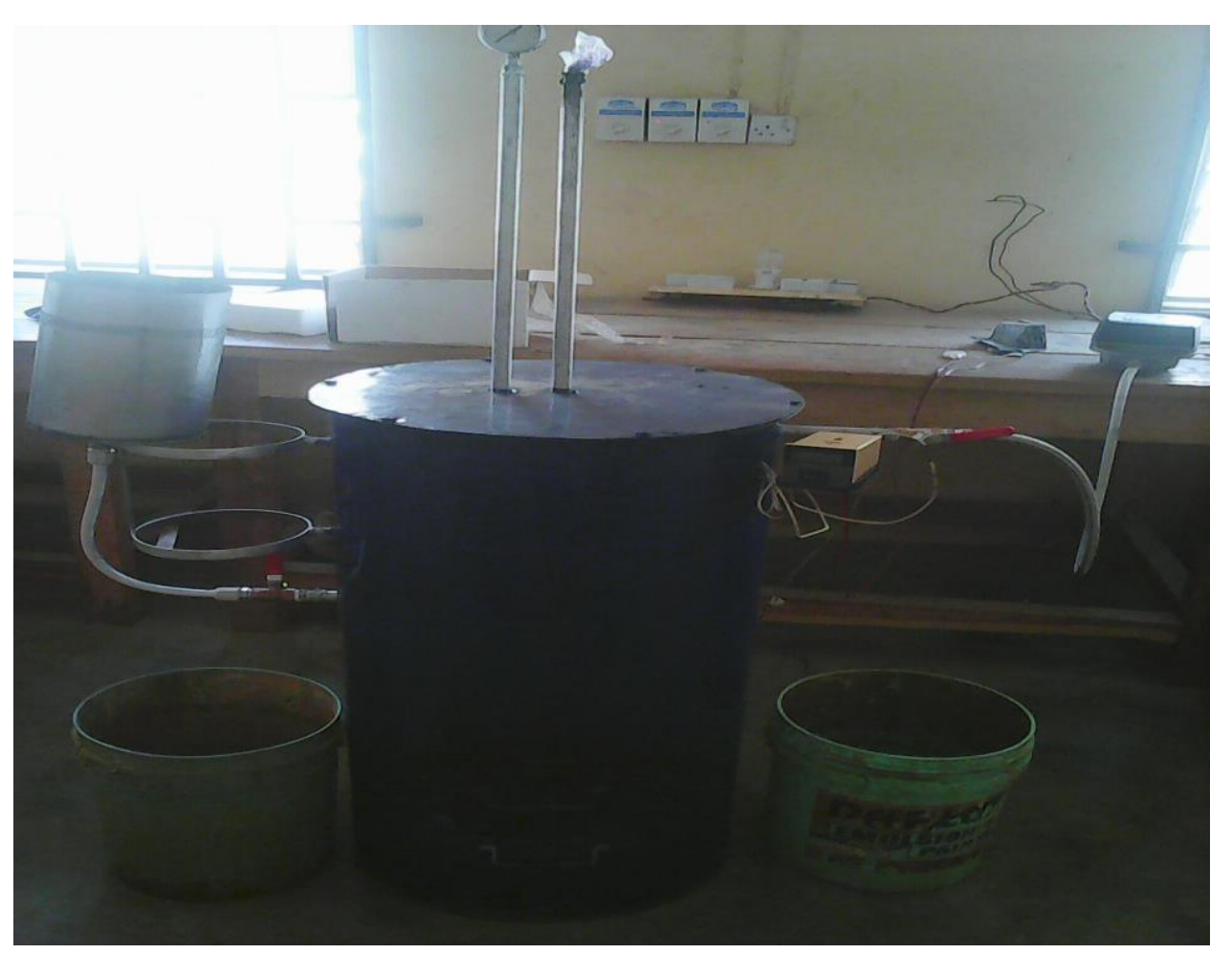

Plate 2: Steam Boiler which was the source of the steam being injected into the sandbox 
International Journal of Engineering Applied Sciences and Technology, 2021

Vol. 6, Issue 4, ISSN No. 2455-2143, Pages 85-98

Published Online August 2021 in IJEAST (http://www.ijeast.com)

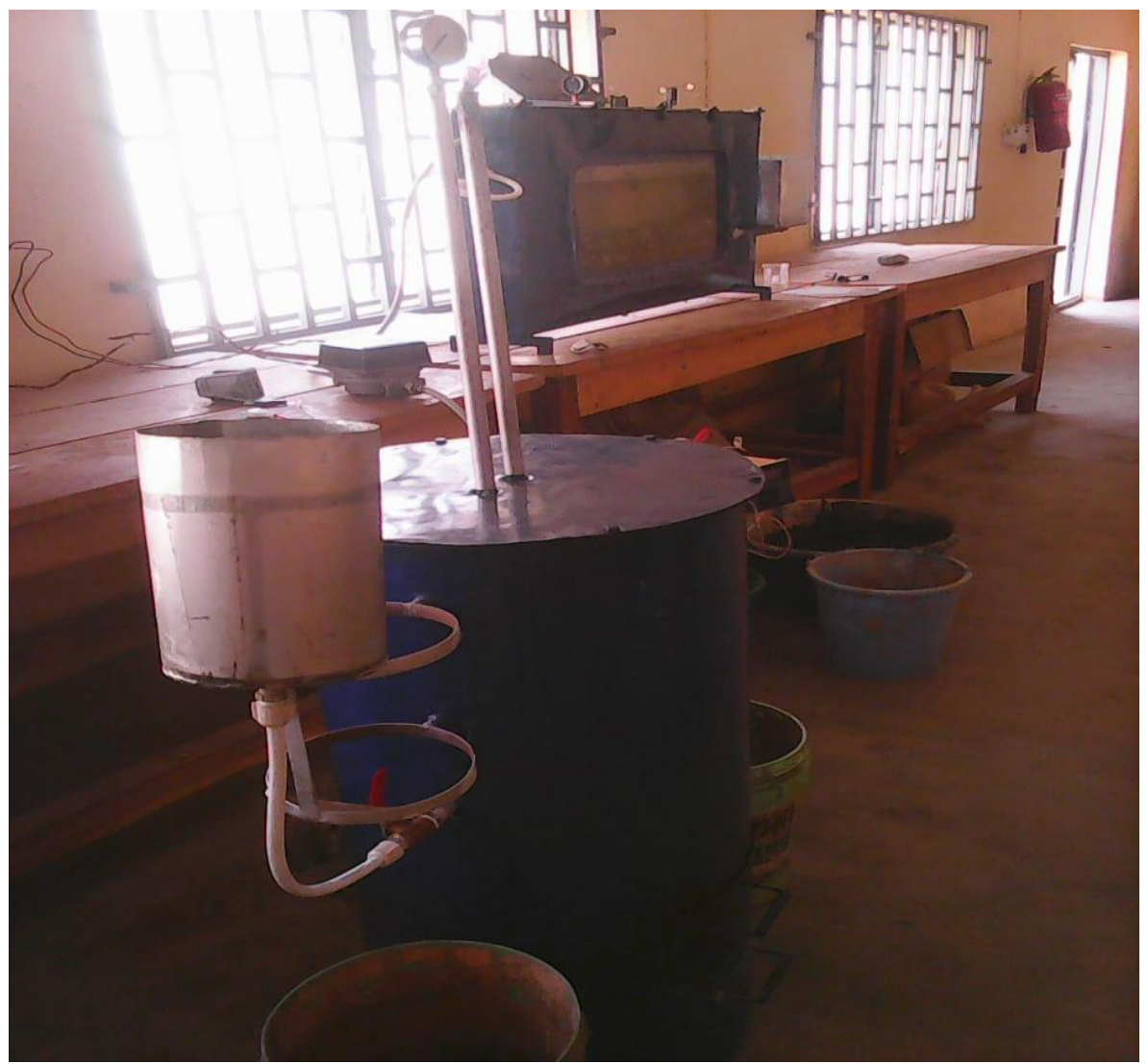

Plate 3: The complete set-up for the remediation of water contaminated with NAPLs consisting of steam boiler, sandbox and the vibration producing electric motor 